\title{
EL PENTECOSTÉS PAGANO DE HILARIO BRAVO
}

\section{THE PAGAN PENTECOST BY HILARIO BRAVO}

\author{
Angélica García-Manso \\ (Grupo de Investigación MUSAEXI - Universidad de Extremadura) \\ angelicamanso@hotmail.es
}

Recibido: 6 de diciembre 2020/ Aceptado: 9 de marzo 2021

Resumen: Se examina la obra Flammae, de la serie Lasparedes de la idea (2014-2016), del pintor Hilario Bravo, a partir de las referencias conceptuales que son posibles descubrir en esta, así como el diálogo que establece entre la tradición mitológica pagana y la inspiración cristiana en la pintura clásica. Desde esta perspectiva se entiende la intertextualización que el artista hace entre las Dánae de Jacopo Comin Tintoretto o Rembrandt Harmenszoons van Rijn con el Pentecostés de Doménilos Theotokópoulos, más conocido como El Greco. El procedimiento se aprecia también en otras obras del pintor de origen extremeño y refleja el dominio de la intertextualidad que no solamente le confiere personalidad estética sino la relectura que lleva a cabo de la iconografía que sustenta las obras citadas y de la ironía que subyace de aplicar la fisicidad a lo trascendente y a la inversa.

Palabras clave: Hilario Bravo, pintura conceptual, análisis iconográfico, Rembrandt, El Greco

Abstract: The work Flammae, from the series The Walls of the Idea (2014-2016), by the painter Hilario Bravo, is examined on the basis of the conceptual references that can be discovered in it, as well as the dialogue that it establishes between pagan mythological tradition and Christian inspiration in the classical painting. From this perspective is understood the intertextualization that the artist makes between the Danae by Jacopo Comin Tintoretto or Rembrandt Harmenszoons van Rijn with the Pentecost of Doménikos Theotokópoulos, El Greco. This procedure can also be seen in other works by the painter and reflects a dominion of intertextuality that not only gives him an aesthetic personality but also the re-reading he carries out of the iconography that underlies the aforementioned works and of the irony that underlies the application of physicality to the transcendent and vice versa.

Keywords: Hilario Bravo, conceptual painting, iconographic analysis, Rembrandt, El Greco 


\section{La obra de Hilario Bravo en el contexto de la pintura contemporánea}

La trayectoria creativa de Hilario Bravo (Cáceres, 1955), que se inició ya con personalidad propia en los primeros años ochenta del pasado siglo (Bravo, 2014), es lo suficiente amplia y contrastada como para poder ser considerada de manera eficiente en un estudio dedicado monográficamente a este (Lozano Bartolozzi, 2008b). Su formación e inicios tienen lugar en el País Vasco y Navarra, donde efectúa sus primeras exposiciones individuales en Pamplona, Bilbao y San Sebastián en el año 1985 (tras diferentes propuestas colectivas desde mediados de la década anterior), y, acto seguido, pasa a dar a conocer su obra en Madrid, Valencia o Alicante durante el lustro siguiente, momento en el que se establece en Extremadura. En el ámbito internacional el pintor expone en Bayona, Lisboa y Roma, en una trayectoria exterior que, por el momento, ha culminado en el año 2018 con su exposición en Bruselas, en el Parlamento Europeo, con una serie dedicada a los distintos países que la configuran con el trasfondo estelar de la bandera europea. Ha disfrutado además de diferentes reconocimientos en forma de premios, becas y estancias, entre los que sobresale su pensionado en la Academia Española de Bellas Artes en Roma en 1995. Su relación con artistas del grupo vasco GAUR (Lozano Barolozzi, 2008a, p. 388), aun siendo de una generación anterior, o, con posterioridad, con otros artistas de la talla de Wolf Vostell en sus inicios y, años después, con José Manuel Ciria (Ciria, 2005) constituyen importantes jalones en la proyección de una obra, que, además de pictórica y gráfica, también se ha desempeñado en labores editoriales y de diseño escenográfico. Su obra figura en colecciones como las del Museo Vostell-Malpartida, Biblioteca Nacional de España, MEIAC, Kutxabank, entre otras. El mantenimiento de un blog (Bravo, 2014) representa, en fin, un excelente soporte para el acceso virtual a su creación artística.

En este contexto entre los años 2012 y 2015 el pintor elabora un proyecto denominado Las paredes de la idea, el cual fue presentado a través de diferentes exposiciones que se desarrollaron a lo largo de los años mencionados hasta 2016 (Fernández Campón, 2014). En dicho proyecto y desde su propio título se efectúa una reflexión de índole metapictórica, que implica como clave hermenéutica una idea motriz: el trasvase de la creación artística desde la concepción mental al lienzo, pero no como un tópico artístico, pues incluye la idea de retorno desde el lienzo a la pared o muro que lo sostiene y, desde la citada pared, que es exterior al lienzo o composición, de regreso a la mente que lo percibe y así lo recrea. Y ello sin que falten ecos platónicos en todo el proceso, es decir, de inmersión en una búsqueda idealizada que transforma la percepción inicial, según comprobaremos con 
posterioridad, de forma que el espacio craneal se transforma en una especie de gruta donde aparece el reflejo de la realidad, algo más evidente si, además, se recurre a iluminarlo con llamas, sean reales o plasmadas como tal en los cuadros.

En efecto, la forma en que se ocupa el espacio constituye uno de los motivos poéticos de la obra más actual de Hilario Bravo, aunque el artista no deja de lado las invocaciones literarias -habituales en él- y uno de sus leit-motivs más reseñables, el de escribir mediante la pintura (Castro, 2004), el cual caracteriza su obra hasta llegar a Las paredes de la idea. Por lo demás, en esta serie recupera propuestas muy anteriores en el tiempo, como Opus lucis, del año 1996, con la que comparte motivos creativos (Cano, 1997; Logroño, 1997).

En síntesis, Las paredes de la idea, también titulada Cabezas, reúne la creación de Hilario Bravo entre 2012 y 2016 bajo la premisa de que el proceso de iluminar la percepción nace de un viaje de ida y vuelta de la realidad a su plasmación artística. Así, el predominio de figuras de cabezas implica un acto de pensamiento que se proyecta hacia un concepto exterior al tiempo que es devuelto hacia el interior de la mente y que dicho viaje de ida y vuelta modela la obra artística concreta (Bravo, 2014; Fernández Campón, 2014). De ahí la posibilidad de analizar una obra como un acto de creación único en torno a un concepto, al tiempo que todas las creaciones que responden al proceso descrito configuran la serie. Por otra parte, se puede apreciar cómo en la trayectoria creativa más reciente de Hilario Bravo Las paredes de la idea actúan de puente con su producción posterior; algo que se hace más evidente aún en una obra como Flammae en la que se anuncia el happening de prender pequeñas llamas en las pinturas.

Así, con una voluntad eminentemente conceptual, movimiento al que se adscribe Hilario Bravo (Lozano Bartolozzi, 2008b; Morgan, 2003), las pinturas no se presentan como creaciones autónomas, sino que dialogan entre sí en series, con propuestas anteriores y, sobre todo, con los espacios para las que inicialmente son concebidas, aunque luego sean trasladables a otros entornos. De ahí también el carácter voluminoso, como envases denominados literalmente «cajas»- en los que en ocasiones se presentaran algunas obras que integran Las paredes de la idea. Ello sin olvidar el diálogo que establecen con los diferentes ámbitos de la palabra -el nombre, la leyenda o el relato mitológico o la literatura (Castro, 1994)-. Sin tales premisas se hace difícil entender no sólo la trayectoria del artista, sino que se impide analizar cada una de las obras. No obstante, y por señalar un único ejemplo, se ha estudiado la rica iconografía a la que Hilario Bravo recurre para recrear la existencia de ninfas en enclaves extremeños significativos (García Manso, 2007; Lozano Bartolozzi, 2016). Lo 
llamativo del caso deriva de cómo los elementos iconográficos por separado reaparecen en obras y momentos de diferente cariz, pero que la suma deviene única, como letras o palabras que se combinan para establecer un diálogo a través del tiempo y las figuras.

En este contexto la serie de Las paredes de la idea, esta parece recuperar o actualizar la titulada Opus lucis (que, según hemos señalado, se fecha con una anterioridad de tres lustros), pues con ella comparte sobre todo la importancia del punto de luz, del foco encendido o la llama, además de hacerse nuevamente eco de la omnipresente trascendencia de lo escrito, del alfabeto tratado como pictograma o imagen artística. Por lo demás, el vacío de los fondos implica que los elementos resalten como islas en la superficie del lienzo o soporte, con la posibilidad de hacer una lectura en diferentes direcciones o sentidos, en vertical o en horizontal. De ahí la superposición de planos, según apreciaremos en un ejemplo concreto, objeto de análisis, probablemente por tratarse de una de las creaciones que ofrece una de las síntesis más logradas de ambas series. Se trata de Flammae, una pintura que escapa precisamente a la posibilidad de ser quemada porque el fuego constituye el contenido conceptual del cuadro.

Finalmente, es importante señalar que las creaciones de la serie en su conjunto aparecen denominadas como «pensamientos»y, en ocasiones, también como «cabezas», y estas se suelen denominar en los catálogos con un segundo título, lo cual confunde en ocasiones la identificación de las obras, más aún cuando la serie repite el mismo leit-motiv de la llama de fuego. Ello provoca algunos problemas de identificación a partir de los títulos, no así de las composiciones propiamente dichas. En el presente análisis sucede con Tres llamas y Tres cabezas, con títulos que parecen intercambiables; de ahí que se proponga el nombre de Flammae para la obra objeto de análisis y de los otros nombres para el establecimiento de correspondencias entre las distintas obras.

\section{En torno a Flammae}

Flammae se presenta como una obra en apariencia sencilla, pero en la que, como es habitual en Hilario Bravo, se superponen varios planos, organizados a base de formas geométricas, figurativas y numérico-alfabéticas. El plano geométrico funciona como un marco irregular sobre el que, en su margen derecho, se tiende un estrecho paralelepípedo morado y sobre el que una especie de enorme tachadura corona, levemente desplazada también hacia la derecha, el citado marco [Fig. 1]. 


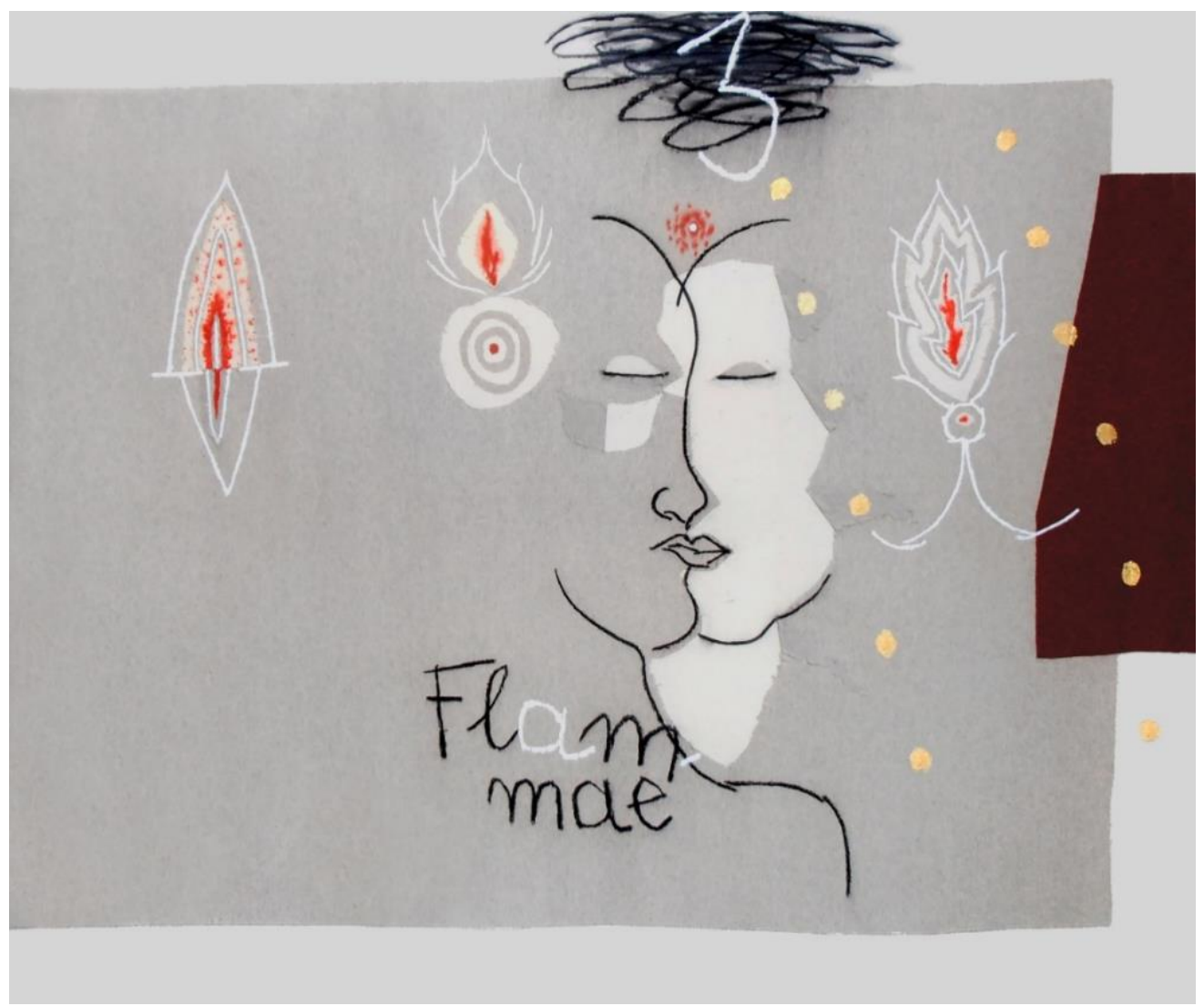

Fig. 1: Flammae, 2014. Obra en colección privada.

Desde una perspectiva figurativa en la propuesta prevalecen dos rostros enfrentados, compartiendo un trazo del perfil a la manera de una iunctura epigráfica (habitual en el artista, según se aprecia, por ejemplo, en la serie Dríada, elaborada en el año 2006), así como tres lucernas con aspectos de vulvas que flotan en el espacio a la altura de los rostros. A caballo entre la expresión geométrica y figurativa y como preludiando la forma de escritura que surge en la parte inferior de la pintura, dos listados de puntos brillantes se desplazan de manera diagonal en paralelo uno de otro, enmarcando una de las lucernas-vulvas, la que se encuentra al lado derecho de la doble faz.

La pintura alberga motivos numéricos y letras: un número tres en la parte superior y la palabra flammae en dos líneas partidas, en la parte inferior. Se trata de un juego de palabras, habitual en el pintor, donde los cuadros se ofrecen también como poemas visuales acerca del titilar de un cabo de una vela o, por ser más precisos, de una lucerna; o, acaso, del temblor de la sangre que se evoca en flam como flan, casi como un juego de palabras. Más importante resulta la palabra mae, que coincide con una palabra homófona en portugués, la que significa madre. En efecto, Hilario Bravo juega en ocasiones, como en La ninfa sedienta, con el idioma portugués (García Manso, 2007). No se trata de lecturas aleatorias, según intentaremos 
mostrar a continuación mediante los intertextos pictóricos a los que recurre el artista y que convierten el cuadro, en nuestra opinión, en una obra clave, que engloba tanto la serie como la estética de Bravo en su conjunto.

En síntesis, la pintura ofrece enmarcados dos rostros andróginos (no porque sean femenino y masculino, sino porque su inspiración de fondo procede del conocido mito de Platón, además de apoyarse en una tradición iconográfica basada en la figura de Jano bifronte, aunque con las faces enfrentadas en el presente caso). A su vez, existe una especie de desvelamiento lateral de una escena en la que ambos rostros se ven rodeados de lucernavulvas y de un camino de puntos dorados. En fin, el conjunto aparece presidido por una especie de nube sobre la que se rasga el contorno de un guarismo.

La propia descripción de la escena delata sus claves: por un lado, la fijación de un éxtasis que es, al mismo tiempo, erótico y místico; por otro lado, la superación de los límites de la propia pintura (evocando cajas y puntos de llamas, como en otras propuestas de Las paredes de la idea, amén del recurso a lo numérico y alfabético). Pero también a este último respecto se invoca una relectura iconográfica. En ello radica la clave de Flammae, en su capacidad de sintetizar los modelos icónicos: la lluvia dorada y las lenguas de fuego. Sendos temas coparán las siguientes reflexiones, cuyo leit-motiv primordial viene dado por un análisis hacia la obra autónoma, algo que escapa en numerosas ocasiones en la producción extensa de la pintura contemporánea, en estética y técnicas que agilizan la elaboración de pinturas y su organización en series.

\section{El modelo del nuevo testamento: las lenguas de fuego de Pentecostés}

La festividad de Pentecostés, aunque con orígenes en la tradición judaica, se presenta como la celebración cristiana en la que se conmemora la manifestación pública del Espíritu Santo en forma de lenguas que fuego que se ciernen sobre los Apóstoles para que emprendan su misión religiosa. Sus elementos iconográficos son conocidos: la paloma (figuración de la persona trinitaria, de acuerdo con el dogma religioso), el rayo y las lenguas de fuego, con el resultado de un arrobamiento o éxtasis místico que implica una experiencia de elevación y, al tiempo, de comunión con el colectivo de creyentes (Réau, 1996; p. 552).

La pintura de Hilario Bravo objeto de análisis expresa conceptualmente tales elementos: así, el tres que emerge de la nube hace alusión expresa al misterio de la Trinidad; las lucernas-vulvas se presentan como lenguas de fuego que, siguiendo la máxima de Heráclito, se presentan como ausencia y plenitud (Fernández Campón, 2014); en tanto el 
paralelepípedo en el margen derecho evoca un manto o un cortinaje que enmarca la escena, de acuerdo con una composición pictórica de carácter clásico, donde la pintura precisa de escenografía. La composición destila cierto aire de descomposición en las figuras, que parecen flotar por separado, a la vez que se muestran en su conjunto como partes de una misma escenografía y como motivo de desvelamiento a partir del paralelepípedo citado, presentándose este a la manera de un cortinaje que se corre o como la vestimenta de un testigo de la manifestación extática que se expone ante sus ojos.

El referente artístico más conocido de Pentecostés es una de las más célebres pinturas de Doménikos Theotokópoulos, El Greco, de la que hay dos versiones, aunque la más importante es la custodiada en el Museo del Prado en Madrid (España), fechada en los años 1597-1600. En el cuadro, la Virgen María y María Magdalena ocupan el centro: se trata de dos mujeres en un entorno de hombres. Son sus rostros los que focalizan el cuadro, a pesar del abigarramiento de cuantos les rodean, con una marcada verticalidad. El sobrecogimiento ante lo profundo domina la escena, que en los rostros femeninos adquiere relieve de éxtasis (Davies, 1999; Menéndez Pidal, 2003).

Por su parte, en Hilario Bravo no se determina bien si se trata de los rostros de dos mujeres o del de un hombre y del de una mujer, si bien en El Greco, las dos mujeres vuelven el rostro una hacia la otra como trascendiendo la experiencia individual en colectiva, lo cual, en verdad, aporta cierta indiferencia al sexo de las figuras. Se trata de un gesto que permite entender en cierta medida la pintura de Hilario Bravo, a partir de la ya mencionada iunctura o trazo compartido con un fuerte carácter polisémico y, sobre todo, a partir de la importancia que se concede al número de tres lucernas-vulvas a la manera de una triple fecundación trinitaria. Por lo demás, la tela de la capa de la segunda figura en el inferior a la derecha, a la que no se ve el rostro (pues lo tiene vuelto), aporta a la propuesta de Hilario Bravo el contraste del color del paralelepípedo, a la vez que centra la vista en el momento del desvelamiento del misterio.

El ábside oscuro y el Espíritu Santo en figura de paloma trinitaria de El Greco aparecen conceptualizados como un número tres emergiendo de un borrón o enorme tachadura en la propuesta de Hilario Bravo, sintetizados así de forma evidente, más aún una vez descubierta la lectura intertextual que el pintor hace del Pentecostés en el conjunto de Flammae y desde su propio título [Fig. 2]. 

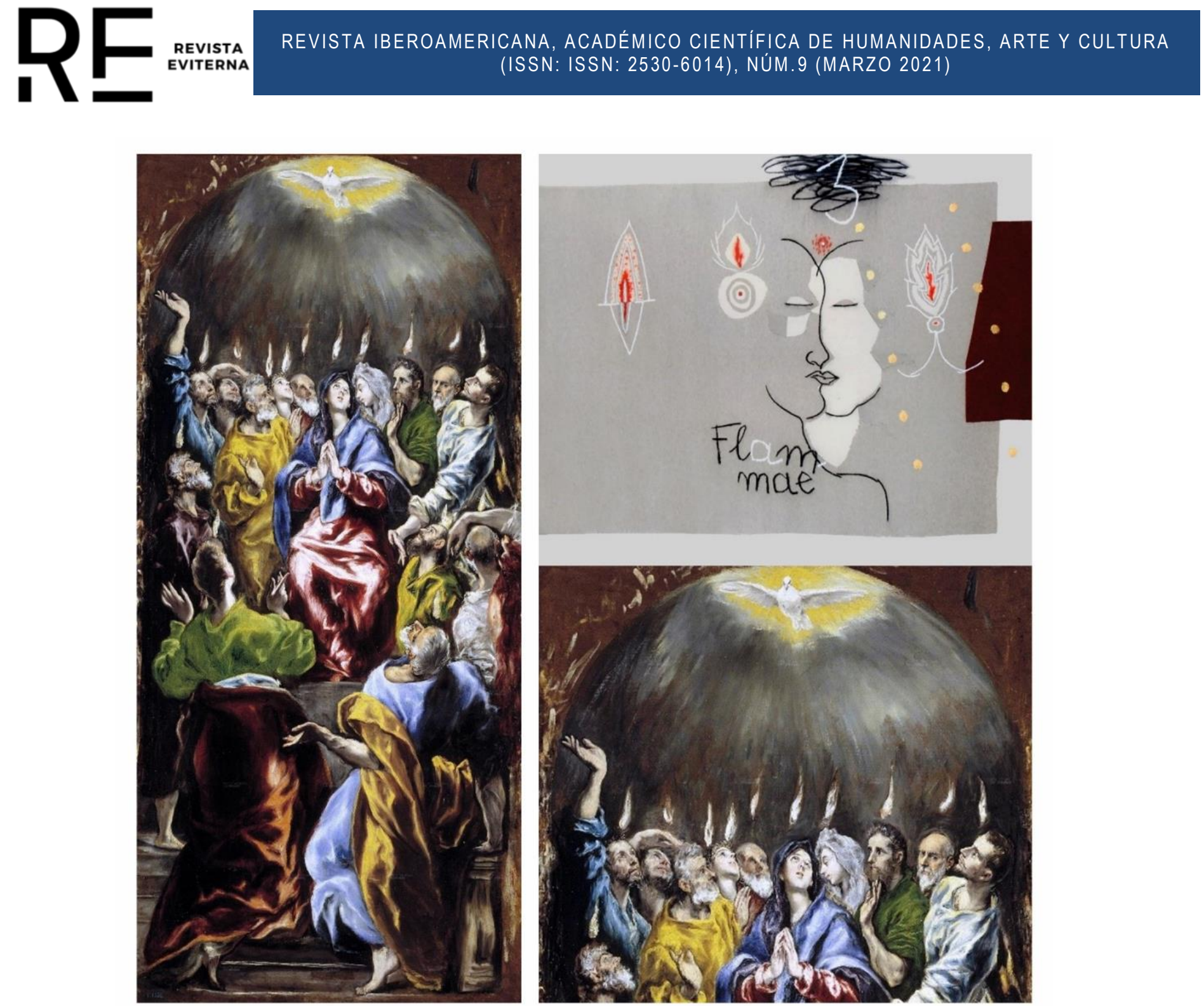

Fig. 2: Pentecostés (general y detalle), de El Greco, 1600, Museo del Prado-Madrid; Flammae, de Hilario Bravo, 2014. Obra en colección privada.

\section{El modelo mitológico: Dánae y la lluvia dorada}

Flammae también ofrece una relectura iconográfica desde una perspectiva mitológica tratándose, por lo demás, de un tema habitual en el pintor (Gallardo, 1995)-, más concretamente en torno a la figura de Dánae, según se puede descubrir a partir de algunos de sus elementos conceptuales básicos: un lecho, una cortina, la nube, el rayo, la lluvia de oro, el enlace sexual marcado por la iunctura de los rostros, etcétera (Peláez, 2014). En la pintura de Hilario Bravo el dios Júpiter se hace presente como oscura nube y como rayo, el cual constituye su atributo iconográfico, aunque dibujado como un número tres cuyo sentido es polisémico, según hemos señalado ya. El camino de puntos de oro en diagonal recrea de forma elocuente la lluvia que, procedente del rayo y la nube, fecunda la lucerna vaginal que se encuentra más a la derecha. 
Por lo demás, en la tradición pictórica cuatro son los hitos más reconocibles de la fecundación que Júpiter hace de la enclaustrada Dánae; se trata de las pinturas de Tiziano Vecellio di Gregorio (1565), de Jacopo Comin, Tintoretto, (1578), Rembrandt Harmenszoon van Rijn (1636) y, ya en creadores más próximos en el tiempo, de Gustave Klimt (1908) [Fig. 3]. Todos ellos presentan elementos concomitantes que son reducidos a su mínima expresión conceptual por parte de Hilario Bravo. La importancia de la cortina como marco, evidentes en Tiziano, Tintoretto y Rembrandt, también se hace presente en el contraste de colores de Klimt según se puede apreciar en el margen inferior izquierdo de su pintura y está presente en el paralelepípedo inserto en la pintura Flammae de Hilario Bravo. Dos son los personajes que aparecen de manera figurativa en los pintores citados, excepción hecha de Klimt (en el que falta la segunda figura); se trata de la propia Dánae y la sirviente que recoge las gotasmonedas, por señalar un elemento común evidente. Así, el rostro doble se presenta tanto como homenaje a las figuras de la escena como, según hemos apuntado, la definición casi platónica de la fusión que representa al sexo.
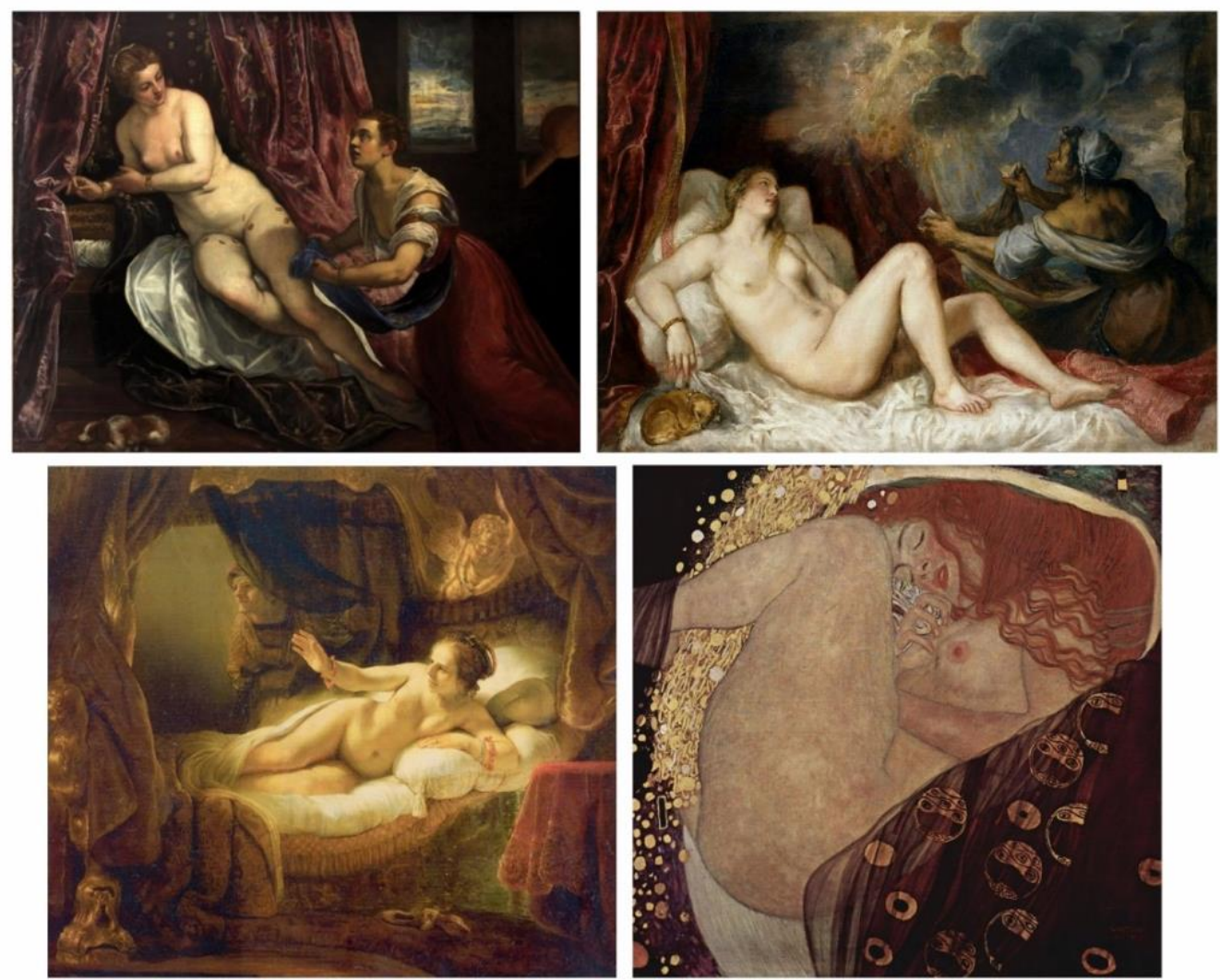

Fig. 3: Diversas versiones de Dánae: Tiziano, 1553-1554, Museo del Prado-Madrid; Tintoretto, 1570, Musée des Beaux-Arts-Lyon; Rembrandt, 1636, Hermitage Museum-San Petersburgo; Klimt, 1907-1908, Leopold Museum-Viena. 
Por otra parte, tras la imagen de una tempestad celestial que vierte su riqueza en la propuesta de Tintoretto, en Rembrandt se muestran de lado los rostros de las dos protagonistas, a las que el pintor plasma mirando en sentidos diferentes, con un carácter contemplativo a la vez que ambiguamente recolector, del semen y del oro, sin que falten, flotando, amorcillos, al igual que están suspensas en el cuadro de Hilario Bravo las lucernas-vulvas. Incluso el cortinaje central recogido en Rembrandt, de tonos más oscuros, se retoma en la propuesta del pintor cacereño. En fin, un cupido flotando aporta una clave que, sumada al cromatismo terroso hace que la propuesta de Hilario Bravo pueda resultar más próxima a la de Rembrandt que a las de Tiziano o Tintoretto.

También en Tintoretto [Fig. 3, superior derecha] la verticalidad de las monedas en su caída, formando además dos hileras, y su procedencia desde un fondo oscuro, entre las cortinas que se abren con forma de vulva, se muestran como motivos presentes en Flammae, para, al cabo, el dinero terminar depositándose en el entorno del pubis de la figura femenina desnuda.

En lo que se refiere a las claves alfabéticas, el número tres en forma de rayo remite iconográficamente a Júpiter, al igual que la idea de mae, a través del término portugués, evoca la figura mitológica de Dánae, madre de Perseo. A este respecto, la grafía con doble $m$, de carácter filológicamente arcaizante en latín, sirve al pintor para estructurar la palabra con un mensaje que duplica los referentes conceptuales y permite la figuración de dos mae (la Virgen y Dánae); pero también, y aunque flam se presenta como una abreviatura pictórica, relativa a Rembrandt como pintor que, aunque no pertenezca stricto sensu a la escuela flamenca, procede de los Países Bajos. Finalmente, el propio Hilario Bravo cita entre sus fuentes de inspiración a Rembrandt ya en 1994 (Bonet, 1994).

\section{Otros paralelismos pictóricos en la obra de Hilario Bravo}

Además de lo abordado en los epígrafes previos, es preciso seguir descubriendo aspectos del proceso de creación en Hilario Bravo a partir de otras propuestas artísticas en paralelo a lo analizado en relación con Flammae y, de nuevo, con claras referencias a obras emblemáticas de la Historia de la Pintura. Por señalar únicamente dos ejemplos, sucede de forma elocuente en una obra sin título ${ }^{1}$, o que, según hemos apuntado en un epígrafe precedente, podría confundirse con Tres llamas. Pues bien, en este trabajo, Hilario Bravo sintetiza en los rostros las figuras de las Gracias de la conocida Alegoría de la Primavera de Sandro Botticelli (Galleria

\footnotetext{
${ }^{1} \mathrm{O}$ de título desconocido, al no aparecer en la detallada presentación de Miguel Fernández Campón (2014).
} 
degli Uffizi, Florencia), a la vez que convierte mirtos y flores de azahar y pequeñas naranjas que brotan en pequeñas llamas, conforme a una de las claves temáticas de la serie Las paredes de la idea, sin que falten en las corolas letras aisladas, de difícil desciframiento más allá del reconocimiento de la clave alfabética como uno de los elementos significativos en la estética de Hilario Bravo.

El número tres de las lucernas-vulvas (que da título también a Flammae) y la triple figura femenina que subyace en la composición inspirada en las Gracias permite establecer una conexión certera entre ambas pinturas, más cuando estas se presentan con una cabellera flamígera [Fig. 4].
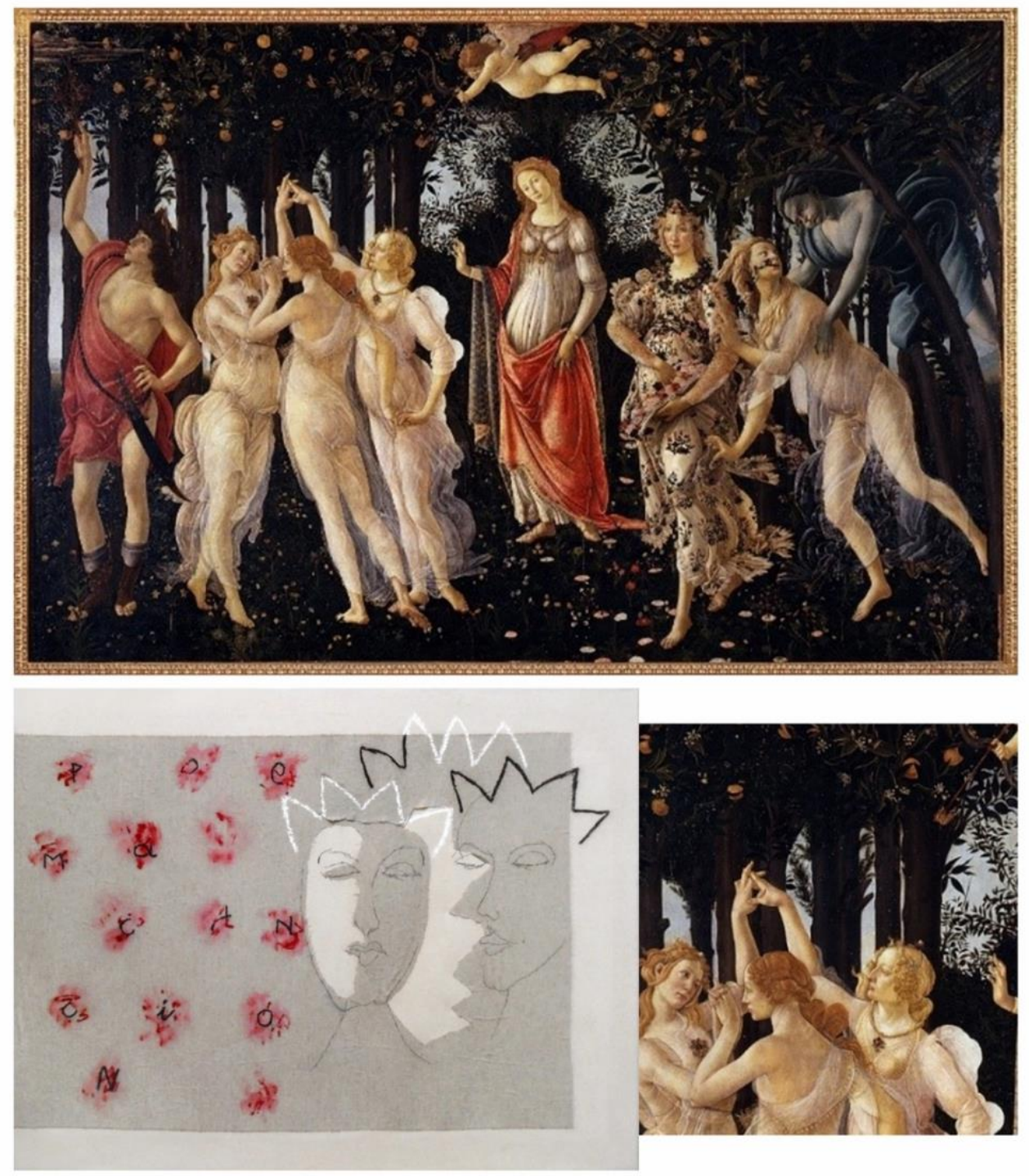

Fig. 4: Allegoria della Primavera (general y detalle), de Sandro Botticelli, 1482, Galleria degli Uffizi, Florencia; Tres llamas, de Hilario Bravo, 2014. Obra en colección privada. 
El procedimiento se confirma en otras propuestas de la serie como Pensamiento Sino, en la que la referencia conceptual remite de forma plausible a la figura de Prometeo. La tradición artística evoca al respecto, al igual que sucede con el cuadro de El Greco en relación con Flammae, a una pintura de Gustave Moreau en la que el fuego no es sólo físico, sino que se presenta, sobre todo, como una iluminación mental, que es la que, al cabo, otorgaría el titán mitológico a la humanidad. Frente a la tradición pictórica que aborda a Prometeo en escenas por separado, en Moreau aparece sintetizada la doble iconografía del titán: el fuego de un lado y el castigo del que se hace acreedor por entregarlo a los hombres de otro (Lacagnina, 2013). Así, la lengua de fuego en la frente cumple a este respecto de forma clara la intención de Las paredes de la idea, según hemos definido en la Introducción y coincide en buena medida con la iconografía de El Greco.

Por lo demás, la mole borrosa a la derecha del rostro, especie de tachón pictórico, o de oscuridad de la que se emerge, evoca la roca, al igual que las rayas horizontales las garras de un buitre que devora su hígado. Además, Pensamiento Sino se presenta con forma de caja, con un doble diálogo cuando se doblan las solapas, con el resultado de hacerse corresponder el rostro con el rostro en el flanco izquierdo y la garra en el derecho. En fin, de dentro del título, de Sino, se desprende el sentido de fatalidad, derivado como es etimológicamente de la palabra signum, el cual posee un doble matiz, como destino (la condena por liberar al ser humano se presenta como un castigo repetido e interminable) y como símbolo (como el fuego, la roca, un buitre que le abre las entrañas, etcétera) [Fig. 5].
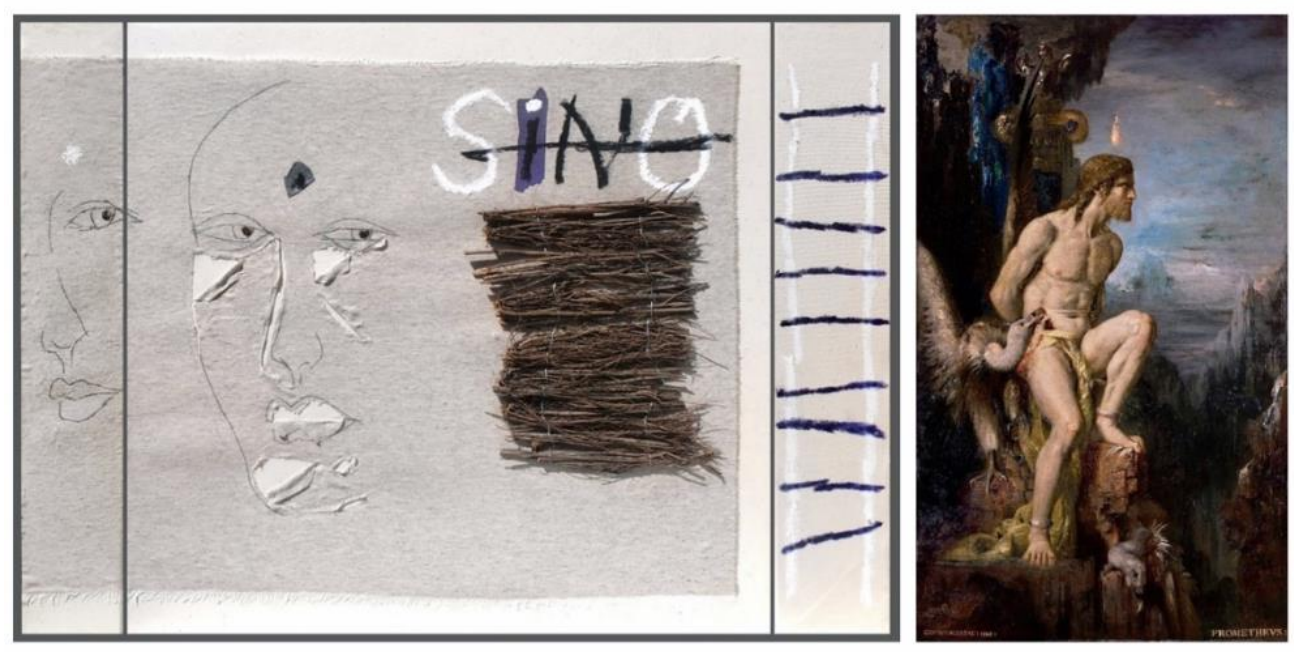

Fig. 5: Pensamiento Sino, de Hilario Bravo, 2014. Obra en colección privada; Prométhée, de Gustave Moreau, 1868. Obra en colección privada. 


\section{Conclusión: la fusión de claves conceptuales como leit-motiv de las paredes de la idea}

Tal como se ha analizado, Hilario Bravo es capaz de sintetizar dos polos de la experiencia estética humana de raigambre occidental: el clásico, que asocia a lo carnal, y el religioso, que asocia a lo trascendental. Uno y otro se funden a la vez que se comentan mutuamente, y lo hacen mediante un proceso de reducción conceptual en el que los elementos son intercambiables entre ambas referencias. Incluso cuando el artista parafrasea mediante el título de la obra lo hace con un doble juego: Flam como abreviatura que se corta en relación con una posible fuente de inspiración en Rembrandt y mae, en portugués, como denominación de la madre.

Se podría pensar que los referentes que se acaban de establecer resultan forzados dada la concentración conceptual que presenta la obra de Hilario Bravo, cuya polisemia bebe en verdad de otros campos además del campo de la Historia de la Pintura. No se trata, empero, de un jeroglífico ${ }^{2}$, sino de lo que en términos retóricos se denominaría ironía, es decir, de una obra que niega expresar lo que, precisamente, enuncia. La intertextualidad de referentes constituye la clave de dicha ironía: los elementos conceptuales se asocian mediante contaminatio (o extracción de motivos de fuentes diversas) y, acto seguido, se recomponen en una propuesta de donde surge una lectura imprevista frente a la pintura o pinturas originales. De alguna manera, las pinturas de Hilario Bravo poseen un carácter programático sobre lo que debe entenderse como pintura conceptual.

Derivado de todo ello se desprende la elaborada riqueza conceptual que domina la estética de Hilario Bravo y, en lo que a Flammae se refiere, se confirma la doble interpretación e interrelación que se hace del motivo del fuego en dos vertientes: su sentido carnal -o físicoy su lectura trascendente -o ideal- de lo humano. Ello sin obviar el trasvase que se produce desde la expresión artística a la idea que la sustenta; o, en otras palabras, la proyección que efectúa la obra a partir del conocimiento iconográfico y de la Historia de la Pintura como leitmotiv central de una serie que, además, lleva el elocuente título de Las paredes de la idea. De alguna manera, Flammae aparece concebido en forma de declaración sobre la creación del pintor. En definitiva, se produce un claro mestizaje entre la procedencia de la idea y su destino, lo cual deviene rasgo dominante en la estética de Bravo a partir del diálogo que plantea el artista entre el objeto y su representación a la vez que enmarca nítidamente su obra

\footnotetext{
${ }^{2}$ O poesía visual, según se han definido en ocasiones algunos de los trabajos de Hilario Bravo (Alfonso, 2004).
} 
en el arte conceptual. Y, en lo que se refiere específicamente a Las paredes de la idea, esta serie actúa de puente fundamental entre la obra precedente y los caminos en los que se ha adentrado el artista durante el último lustro, con una importante proyección internacional.

\section{Referencias bibliográficas}

Alfonso, C. de (5 de noviembre de 2004), Metáforas pictóricas de Hilario Bravo. El Punto de las Artes, 761.

Bonet, Juan Manuel (1994), El mundo desde Cáceres. En Bonet, Juan Manuel et al. Hilario Bravo. Jardines del mundo. Catálogo. Mérida: Asamblea de Extremadura, pp. 14-15.

Bravo, Hilario (2000). Las Cuentas de Caronte. Mérida: Junta de Extremadura.

Bravo, Hilario (febrero de 2014). Las paredes de la idea. Notas en la niebla [Entrada de blog]. Recuperado de: http://hilariobravo.blogspot.com/2014/02/.

Cano Ramos, José Javier et al. (1997). Hilario Bravo. Opus Lucis. Catálogo. Mérida: Junta de Extremadura.

Castro Flórez, Fernando (1994). Hilario Bravo. El estanque de Diana. Catálogo. Mérida: Asamblea de Extremadura.

Castro Flórez, Fernando (2004). Hilario Bravo. La escritura (in)memorial. Catálogo. Cáceres: Museo de Cáceres.

Ciria, José Manuel (2 de diciembre de 2005). Hilario Bravo. Barcelona. Recuperado de: http://joseciria.com/?s=Bravo .

Davies, David (1999), La ascensión de la mente hacia Dios: La iconografía religiosa del Greco y la reforma espiritual en España. En Álvarez Lopera, José (ed.). El Greco: Identidad y Transformación. Milano: Skira Editore, pp. 175-204.

Fernández Campón, Miguel Ángel (2014). Hilario Bravo. Cabezas. Las paredes de la idea. Catálogo. Pamplona/Cáceres: Ayuntamiento de Pamplona/Diputación Provincial de Cáceres.

Gallardo López, María Dolores (1995). La mitología clásica en la pintura y escultura actuales. Madrid: Ediciones Clásicas.

García Manso, Angélica (2008), Dríada 2007: Reflexiones en torno a la Ninfa Sedienta de Hilario Bravo. Ars et Sapientia, no 25, pp. 61-69. 
Lacagnina, Davide (2013), Memoria e attualità dell'antico nel Prométhée di Gustave Moreau. Ricerche di Storia dell'Arte, no 109, pp. 5-17.

Logroño, Miguel (1997). Hilario Bravo. Opus Lucis. Catálogo. Mérida: Junta de Extremadura.

Lozano Bartolozzi, María del Mar (ed.) (2008a). Plástica Extremeña. Badajoz: Fundación Caja Badajoz.

Lozano Bartolozzi, María del Mar et al. (2008b). El pulso del arte contemporáneo. Artistas de la colección de la Asamblea de Extremadura. Mérida: Asamblea de Extremadura.

Lozano Bartolozzi, María del Mar (2012), El paisaje hídrico en torno al Tajo y los artistas contemporáneos. En Lozano Bartolozzi, M. M. y Méndez Hernán, V. (eds.). Paisajes culturales del agua. Mérida: Editora Regional de Extremadura, Universidad de Exremadura, Ministerio de Economía y Competitividad, pp. 423-443.

Menéndez Pidal y Goyri, Gonzalo (2003), El Greco y sus dos Pentecostés. Arte, Individuo y Sociedad, no 155 , pp. 155-161.

Morgan, Robert C. (2003). Del arte a la idea: ensayos sobre arte conceptual. Madrid: Akal.

Peláez Malagón, José Enrique (2014). El mito de Dánae en la pintura: Una aproximación desde la Literatura Comparada. CLIO. History and History Teaching, 40. Recuperado de: http://clio.rediris.es/n40/articulos/pelaez2014.pdf.

Réau, Louis (1996). Iconografía del arte cristiano (2). Nuevo Testamento. Barcelona: Serbal. 